ventilation, the limit to capability of work being reached when the resulting ventilation reached the subject's voluntary maximum.

Dr. Cotes was unable to say why the breathing of extra oxygen should produce these effects, but many possibilities had been excluded, such as secondary changes in the pulmonary circulation, blood lactatelevels, or in the stiffness of the lungs. This was the limit of present knowledge on the subject, but it was hoped that the mechanisms operating would soon be elucidated.

The fourth and final paper in the symposium was given by Flight-Lieutenant D. H. Glaister, also of the Royal Air Force Institute of Aviation Medicine, under the title "Some Effects of Positive Acceleration on Respiratory Mechanics". Describing the interest physiologists have had in the effects of posture on breathing, Dr. Glaister went on to show how the human centrifuge could be used to extend data beyond the $\mathrm{l} g$ which normally limited laboratory experiments. Positive acceleration was described as that acting in the same sense as gravity on a man standing on Earth's surface, and is measured in terms of this being $1 \mathrm{~g}$. The postural change from lying to standing was thus equivalent to a change from $1 g$ transverse acceleration to $l g$ positive acceleration.

Circulatory effects prevented many experiments being carried out above 4 or $5 g$, since the degree of relaxation required to produce accurate respiratory measurements resulted in blackout or even unconsciousness. Most comparisons were therefore made between 1 and $3 g$. As positive acceleration was applied the diaphragm was pulled down by the weight of the abdominal contents, and at $3 g$, about $500 \mathrm{ml}$. of air were drawn into the lungs. Despite this, the vital capacity of the lungs fell by $300 \mathrm{ml}$., due partly to an increase in stiffness of the chest wall, and partly to a rise in intra-abdominal pressure which limited the full descent of the diaphragm. The basic mechanics of respiration were then described, and it was shown how the various properties of lung and chest wall could be isolated and measured. Results of experiments using these techniques had shown that no change occurred in the stiffness of the lung, nor in the air resistance of the passages leading to it, at least when the subjects were submitted to positive accelerations of $3 g$.

The work done on the lungs had been measured by recording continuously the changes in their volume and the pressure gradient across them during quiet breathing. This was shown to be unchanged at least up to $3 g$. The total work done by the muscles of respiration, however, had to rise under the effects of increased positive acceleration, due to the stiffening of the chest wall and to the raised intra-abdominal pressure. The overall efficiency of the respiratory process thus fell during positive acceleration. Dr. Glaister concluded by pointing out that while this lowered efficiency was probably of little moment at the lower $g$-levels, and with a subject at rest, it would impose a marked limitation to tolerance of exercise during prolonged positive acceleration.

The symposium concluded with a brief discussion $\begin{array}{ll}\text { on the four papers. } & \text { D. H. Gratster }\end{array}$

\title{
THE NORMAN LOCKYER OBSERVATORY
}

\author{
By Prof. G. K. T. CONN \\ Department of Physics, University of Exeter
}

CIR NORMAN LOCKYER founded and endowed $\$$ the Hill Observatory at Salcombe Regis, Sidmouth. He was its first director. It is now the Nor. man Lockyer Observatory and has been, since 1948, intimately associated with the University of Exeter. Lockyer was a remarkable man. His discovery of helium in the Sun's spectrum in 1868 was made as a "private citizen", for he was not appointed to the Science and Art Department at South Kensington by Disraeli until 1875. On the formation of the Royal College of Science he became director of the Solar Physics Laboratory and professor of astrophysics. When the Solar Physics Laboratory at South Kensington was transferred to Cambridge in 1913 he set about building a new observatory on the superb site at Sidmouth, at the age of seventy-seven. Lockyer was the founder editor of Nature in 1869 and remained responsible for fifty years. He was succeeded as chairman of the Observatory Council by Sir Richard Gregory, his successor as editor of Nature. Indeed, both Lockyer and Gregory took great interest in the affairs of the old University College of the South West, now the University of Exeter, and it was Gregory's initiative that led to the intimate association of the Observatory with the University, "a possession which is unequalled in any but the older universities".

The peninsula Salcombe Regis is relatively free from industrial haze and Lockyer chose a site with a superb horizon and a very low noise-level; it is now of some
44 acres. The buildings consist of offices and leboratories with a well-equipped library, a store room, a cottage and three domes. The McLean dome houses a 12-in. refracting telescope with an objective prism of $20^{\circ}$, mounted with a 10 -in. visual refractor on a Grubb equatorial mounting with electric control. (The donor, Sir Francis MeLean, was the co-founder of the Observatory and became known to the public as the first airman to fly under the Thames bridges, in 1912.) The Kensington telescope is a 9-in. refractor with an objective prism of $45^{\circ}$, made by Henri Frères, and giving great transparency in the near ultra-violet, on a Cooke equatorial with Russell control; a 10-in. Cooke visual telescope is mounted alongside. The Mond photographic telescope consists of a four-camera, astrographic equatorial by Cooke with three Zeiss triplet lenses of apertures 17,14 and $10 \mathrm{~cm}$. and one Zeiss anastigmat, aperture $7 \mathrm{~cm}$. The mounting is designed to allow an uninterrupted circumpolar motion at all declinations; the clock drive is fitted with electric control. There are various pieces of equipment which have not hitherto been set up, for example, a 30-in. reflecting telescope and a 21 -in. siderostat.

Work began in 1919, the first paper, published in the Monthly Notices of the Royal Astronomical Society in 1920, being "Spectroscopic and Magnitude Observa. tions of Nova Cygni III, 1920". Some 90 research papers have been published, about 40 in the period 1920 36 and 45 during 1936-56, when D. L. Edwards 
was director (see p. 112 of this issue). The work has been largely on stellar spectroscopy. Since 1936 the principal lines of work have been the development of methods of measuring stellar gradients and colour temperatures, using the McLean prismatic camera, and a photographic survey of galactic clusters made with the Mond telescope. New ground has been broken in recent years with the initiation of photometric research on the twilight luminescence of atmospheric sodium. The Kensington telescope has been used to study the irregular variable star, $\gamma$-Cassiopeiæ; there are some 460 spectrograms of this star in an almost unbroken sequence from 1921 to 1956 .

The Observatory was, and is, maintained as a nonprofit making corporation through endowments and funds provided by donors. Since 1948 the management has been vested in the Council of the Corporation on which the University of Exeter has a definitive majority. The funds available have never been lavish. Rapidly rising costs since the War, together with the development of sophisticated experimental techniques, have meant that the position of the Observatory as an effective centre of original research has become progressively more difficult and indeed critical. Against the background of developments in satellites and in space research, the extensive recent progress of studies of the upper atmosphere and the revival of interest in astronomy and astrophysics, such a difficult position presents an obvious challenge. The site is large enough for astrophysical work and for an extensive programme of research and teaching in geophysics, a growing interest of the University's Department of Physics, and of geomagnetism, an interest of the Department of Mathematics.

The first immediate change of activity for the Observatory will follow from the interests of Dr. $\mathrm{K}$. Weekes and Mr. A. Nichol. Conditions in the high atmosphere can be studied by various means using both radio and optical techniques. Up to the height of the greatest electron concentration in the $F_{2}$ region it is possible, in principle, to infer the distribution of ionization from routine soundings.
Above the peak of the $F_{2}$ region, artificial satellites may be used, or Thomson scattering of radio waves and optical experiments. An examination of the radio waves emitted by satellites may be used to infer the integrated electron density between the receiver and the satellite. This is relatively insensitive to the distribution of electrons, but as the satellite changes height in the course of a transit, the distribution at satellite height may be inferred. The most valuable direct means of studying the distribution of electrons in the high atmosphere is by the Thomson scattering of radio waves by free electrons. Examination of experiments in the United States to heights of about $700 \mathrm{~km}$. suggests that useful results should be obtained to a height of about $2,000 \mathrm{~km}$. It is commonly believed that the emission lines of OI at 6300 and $6364 \AA$. are excited by recombination in the $F$ region. The correlation between the optical intensities and radio measurements of ionization clearly must be examined. Moreover, it is possible, with careful techniques, to measure the line-width of the OI lines and so obtain a direct measure of the temperature of the atmosphere at the height of emission of these lines.

To a classical astronomer nowadays anything below a fixed star is no doubt to be termed 'terrestrial', just as to many people any study above roof-level is termed 'astronomical'. The future is seen to lie in the wedding of optical with radio techniques in the fields of astrophysics and geophysics and of geomagnetism. Moreover, the vitality of the Observa tory has suffered from its relative isolation. The University did indeed, so Gregory said, acquire "a possession which is unequalled in any but the older universities". The means are there to train students and research workers in the old and in the new techniques of exploring space. The raw material of research is to hand. The Observatory began as Lockyer's hobby in his old age: it has acquired a reputation in astrophysics and an affectionate regard in the south-west of England. By acquiring additional eyes we shall see more and see farther. An old man's hobby has become a young University's opportunity.

\section{LONG-RANGE RADIO COMMUNICATION BY SATELLITE MICROWAVE DIPOLES}

\begin{abstract}
$\mathrm{A}^{\mathrm{N}}$ $\mathrm{N}$ article under this title detailing the West Ford Project was published in Nature of September 23, p. 1237. At the eleventh General Assembly of the International Astronomical Union held in Berkeley, California, on August 24, two resolutions were unanimously adopted concerning that Project and similar space experiments that might have harmful effects on astronomy. At the recent General Assembly of the International Council of Scientific Unions in London, a resolution similar to Resolution No. 1 of the International Astronomical Union was adopted, which refers to the whole of science, rather than to astronomy in particular.

The following is the text of the resolutions adopted by the International Astronomical Union:

Resolution No. 1. Viewing with great concern the grave danger that some future space projects might seriously interfere with astronomical observations in the optical as well as in the radio domain,

and believing that a degree of contamination of space which at the present time would be hardly
\end{abstract}

detectable, might, if long-lived, well be disastrous to future observations with improved techniques, and maintaining that no group has the right to change the Earth's environment in any significant way without full international study and agreement; the International Astronomical Union gives clear warning of the grave moral and material consequences which could stem from a disregard of the future of astronomical progress,

and appeals to all Governments concerned with launching space experiments which could possibly affect astronomical research to consult with the International Astronomical Union before undertaking such experiments and to refrain from launching until it is established beyond doubt that no damage will be done to astronomical research.

Resolution 2. The International Astronomical Union expresses its appreciation that the plans for Project West Ford have been publicly announced well ahead of proposed launching and of the United States Government's official policy* that further 